\title{
Risk Factors for Recurrence after Robot-Assisted Radical Hysterectomy for Early-Stage Cervical Cancer: A Multicenter Retrospective Study
}

\author{
Jordi Ponce $^{1}$, Sergi Fernandez-Gonzalez ${ }^{1, *(D)}$, Antonio Gil-Moreno ${ }^{2}{ }^{\circledR}$, Pluvio J. Coronado ${ }^{3}$, \\ Jesús De la Rosa ${ }^{4}$, Henrique Nabais ${ }^{5}$, Ginés Hernández ${ }^{6}{ }^{\mathbb{D}}$, Anna Taltavull ${ }^{7}$, \\ Juan Gilabert-Estelles ${ }^{8}$, Sergio Martínez-Román ${ }^{9}$, Manel Barahona ${ }^{10}$, Marc Barahona ${ }^{1}$ and \\ María Ángeles Martínez-Maestre ${ }^{11}$ \\ 1 Department of Gynecology, University Hospital of Bellvitge (IDIBELL), L'Hospitalet de Llobregat, \\ 08907 Barcelona, Spain; jponce@bellvitgehospital.cat (J.P.); mbarahona@bellvitgehospital.cat (M.B.) \\ 2 Department of Gynecologic Oncology, Hospital Universitari Vall d'Hebron, 08035 Barcelona, Spain; \\ agil@vhebron.net \\ 3 Instituto de Salud de la Mujer, Hospital Clínico San Carlos, Madrid, IdISSC, Universidad Complutense, \\ 28040 Madrid, Spain; pcoronado@gmail.com \\ 4 Department of Gynecology, Hospital Universitario de Basurto, 48013 Bilbao, Spain; jhrosafer@hotmail.com \\ 5 Department of Gynecology, Champalimaud Foundation, 1400-038 Lisbon, Portugal; \\ henrique.nabais@fundacaochampalimaud.pt \\ 6 Department of Gynecology, Hospital Universitario Quirónsalud, 28223 Madrid, Spain; \\ gines.hernandez@quironsalud.es \\ 7 Department of Gynecology, Hospital Universitari Josep Trueta, 17007 Girona, Spain; \\ ataltavull.girona.ics@gencat.cat \\ 8 Department of Gynecology, Hospital General Universitario de Valencia, University of Valencia, \\ 46014 Valencia, Spain; gilabert_juaest@gva.es \\ 9 Department of Gynecology, Hospital Universitari Germans Trias i Pujol, Badalona, 08916 Barcelona, Spain; \\ smartinezro.germanstrias@gencat.cat \\ 10 Department of Gynecology, University Hospital of Puerto Real, 11510 Cádiz, Spain; manuel.barahona@uca.es \\ 11 Department of Gynecology, Hospital Universitario Virgen del Rocio, 41013 Sevilla, Spain; \\ martinez.maestre@hotmail.com \\ * Correspondence: sfernandezg@bellvitgehospital.cat
}

Received: 13 October 2020; Accepted: 14 November 2020; Published: 16 November 2020

check for updates

Simple Summary: In 239 women with early-stage cervical cancer ( $\leq$ IB1 or IIA1, FIGO 2009) undergoing robot-assisted radical hysterectomy in Spanish and Portuguese centers between 2009 and 2018 , the overall survival rate was $94.1 \%$ after a median follow-up of 51 months. Recurrence was diagnosed in 26 patients. In the multivariate analysis, independent risk factors for recurrence were tumor size $>20 \mathrm{~mm}$, adenocarcinoma as histological type, presence of positive pelvic lymph nodes, tumor grades 2 and 3, and not performing sentinel lymph node biopsy. The present oncological and surgical results surpassed the target of quality indicators in cervical cancer proposed by the European Society of Gynecology Oncology. When selecting a robot-assisted surgical approach to perform radical hysterectomy in the surgical treatment of primary early-stage cervical cancer, it is recommended to take into account the tumor grade and histological type, results of the sentinel lymph node biopsy, and the size of the tumor.

Abstract: This retrospective analysis aimed to assess the risk factors for recurrence in patients diagnosed with early-stage cervical cancer ( $\leq$ IB1 or IIA1, FIGO 2009) undergoing robot-assisted radical hysterectomy in Spain and Portugal between 2009 and 2018. A second primary objective was to audit the oncological outcomes according to quality indicators (QI) proposed by the European Society of Gynecology Oncology (ESGO). The study population included 239 women. After a median follow-up 
of 51 months, recurrence occurred in 26 patients (10.9\%). Independent factors for recurrence were clinical tumor size $>20 \mathrm{~mm}$ (hazard ratio (HR) 2.37), adenocarcinoma as histological type (HR 2.51), positive pelvic lymph nodes (HR 4.83), tumor grade 2 (HR 4.99), tumor grade 3 (HR 8.06), and having not performed sentinel lymph node biopsy (SLNB) (HR 4.08). All 5 QI selected were surpassed by our results. In patients with early-stage cervical cancer undergoing robotic radical hysterectomy, clinicians should be aware that tumor grade 2 and 3, tumor size $>20 \mathrm{~mm}$, adenocarcinoma, positive pelvic nodes, and lack of performance of SLNB are risk factors for recurrence. Fulfillment of QI targets of the ESGO might be considered as an objective oncological outcome indicator supporting the minimally invasive approach for early-stage cervical cancer treatment.

Keywords: early-stage cervical cancer; robotic surgery; radical hysterectomy; oncological outcome; recurrence

\section{Introduction}

Since the Food and Drug Administration (FDA) approval of the da Vinci ${ }^{\circledR}$ robot for gynecologic surgery in 2005, robot-assisted minimally invasive surgery (MIS) has become increasingly common in gynecological oncology [1-4]. Observational studies published in the literature before 2018 concluded that either traditional laparoscopic [5-7] or robot-assisted laparoscopic [8-12] approaches provided similar oncological outcomes to open surgery. In 2018, the Laparoscopic Approach to Cervical Cancer (LACC) trial [13], a phase 3 trial comparing MIS (laparoscopic or robotic) radical hysterectomy with open radical hysterectomy in women with early-stage cervical cancer revealed a disease-free survival (DFS) rate at 4.5 years that was lower with MIS than with open surgery $(86.0 \%$ vs. $96.5 \%)$ and a lower 3-year rate of overall survival (OS) (93.8\% vs. 99.0\%). However, of the patients who were assigned to MIS, $84.4 \%$ underwent laparoscopy and $15.6 \%$ robot-assisted surgery. Based on these unexpected results and data of two further observational studies [14,15], in 2019 the European Society of Gynecological Oncology (ESGO) established the open approach as the gold standard for radical hysterectomy [16] and recommended to reserve MIS for highly-specialized centers in gynecological surgery. In January 2020, ESGO also published quality indicators (QI) for the surgical treatment of cervical cancer [17] with the intention to audit and improve clinical practice in an easy and practicable way. Nevertheless, whether results of laparoscopic and robotic surgery can be superimposed remains a matter of debate.

Cancer of the cervix ranks fourth in the list of the most common malignancies and causes of death in women globally [18]. In 2018, 570,000 diagnoses of cervical cancer worldwide and about 311,000 deaths in women were estimated from the disease [19]. However, the incidence of cervical cancer is decreasing in Southern European countries [20], and in Spain, an incidence of 2000 cases diagnosed per year was estimated [21]. About half of women with cervical cancer are diagnosed at early stages ( $\leq$ IB1 or IIA1) and standard treatment includes radical hysterectomy with pelvic lymphadenectomy and/or sentinel lymph node biopsy.

The primary objective of this study was to assess the risk factors for recurrence in all women with early-stage cervical cancer who underwent robotic surgery in the departments of gynecology of all centers of the Iberian Peninsula (9 hospitals in Spain and 1 hospital in Portugal) in which da Vinci ${ }^{\circledR}$ technology was available. The second primary objective was to audit the oncological and surgical results according to recommendations for cervical cancer surgery proposed by the ESGO [17]. The secondary objective was to validate the prognostic value of the 2018 International Federation of Gynecology and Obstetrics (FIGO) staging system [22] in our series. 


\section{Results}

A total of 263 women with a clinical diagnosis of early-stage (IA1, IA2, IB1, IIA1) cervical cancer underwent robot-assisted radical hysterectomy during the study period. Twenty-four patients were upstaged after surgical resection (stage IB2, $n=9 ; \geq \mathrm{IIB}, n=15$ ) (FIGO 2009) [23] and were excluded from the analysis of recurrence, but the audit of QI was performed in the whole series of 263 patients.

\subsection{Clinical and Pathological Characteristics}

The mean age of the study population $(n=239)$ was 48 years. As shown in Table 1 , salient features included median tumor size $\leq 20 \mathrm{~mm} 69.1 \%$ of the patients, squamous cell carcinoma in $58.9 \%$, stage IB1 in $80.3 \%$, negative nodal status in $89.5 \%$, tumor grade 2 in $52.9 \%$, histological tumor size $\leq 20 \mathrm{~mm}$ in $62.8 \%$, and stromal infiltration less than one-third of tissue core in $61.2 \%$. There were 21 patients with stage IA1 cervical cancer, but only two of them were aged $<35$ years; no fertility-sparing procedures were performed in these cases.

Table 1. Clinical and Pathological Data.

\begin{tabular}{|c|c|c|c|c|}
\hline Variables & $\begin{array}{l}\text { All Patients } \\
\quad(n=239)\end{array}$ & $\begin{array}{l}\text { Recurrence } \\
\quad(n=26)\end{array}$ & $\begin{array}{l}\text { Hazard Ratio } \\
\quad(95 \% \text { CI })\end{array}$ & $\begin{array}{c}p \\
\text { Value }\end{array}$ \\
\hline Age, years, median (range) & $48(25-81)$ & $51(34-81)$ & $1.05(1.01-1.09)$ & 0.007 \\
\hline BMI, median (range) & $26(17-59)$ & $27(19-35)$ & $1.01(0.96-1.07)$ & 0.716 \\
\hline Clinical tumor size, $\mathrm{mm}$, median (range) & $15(0-40)$ & $25(0-40)$ & $1.07(1.03-1.1)$ & $<0.001$ \\
\hline$\leq 20 \mathrm{~mm}, n(\%)$ & $159(69.1)$ & $11(44)$ & 1 & \\
\hline$>20 \mathrm{~mm}, n(\%)$ & $71(30.9)$ & $14(56)$ & $3.2(1.45-7.09)$ & 0.004 \\
\hline MRI tumor size, mm, median (range) & $15(0-40)$ & $26(3-40)$ & $1.05(1.01-1.09)$ & 0.013 \\
\hline$\leq 20 \mathrm{~mm}, n(\%)$ & $136(66.7)$ & $8(42.1)$ & 1 & \\
\hline$>20 \mathrm{~mm}, n(\%)$ & $68(33.3)$ & $11(57.9)$ & $2.87(1.15-7.14)$ & 0.023 \\
\hline \multicolumn{5}{|l|}{ Stage of disease, $n(\%)$} \\
\hline IA1 & $21(8.8)$ & 0 & NA & \\
\hline IA2 & $18(7.5)$ & 0 & NA & \\
\hline IB1 & $192(80.3)$ & $25(96.2)$ & NA & \\
\hline IIA1 & $8(3.3)$ & $1(3.8)$ & NA & \\
\hline \multicolumn{5}{|l|}{ Histological type, $n(\%)$} \\
\hline Squamous cell carcinoma & $141(58.9)$ & $10(38.5)$ & 1 & \\
\hline Adenocarcinoma & $89(37.2)$ & $13(50)$ & $1.97(0.84-4.48)$ & 0.108 \\
\hline Other & $9(3.8)$ & $3(11.5)$ & $6.29(1.72-23.02)$ & 0.005 \\
\hline \multicolumn{5}{|l|}{ Nodal status, $n(\%)$} \\
\hline Negative & $214(89.5)$ & $22(84.6)$ & 1 & \\
\hline Positive & $11(4.6)$ & $4(15.4)$ & $4.32(1.48-12-59)$ & 0.023 \\
\hline Lymphovascular space involvement, $n(\%)$ & $42(17.6)$ & $7(26.9)$ & $1.75(0.74-4.19)$ & 0.2 \\
\hline Tumor grade, $n(\%)$ & & & & $<0.001$ \\
\hline 1 & $74(31.1)$ & $2(7.7)$ & 1 & \\
\hline 2 & $126(52.9)$ & $14(53.8)$ & $4.73(1.08-20.85)$ & 0.04 \\
\hline 3 & $38(16)$ & $10(38.5)$ & $10.49(2.29-47.73)$ & 0.002 \\
\hline $\begin{array}{l}\text { Histological tumor size, mm, median } \\
\text { (range) }\end{array}$ & $18(0-40)$ & $25(3-40)$ & & 0.001 \\
\hline$\leq 20 \mathrm{~mm}, n(\%)$ & $150(62.8)$ & $10(38.5)$ & 1 & \\
\hline$>20 \mathrm{~mm}, n(\%)$ & $89(37.2)$ & $16(61.5)$ & $2.89(1.31-6.37)$ & 0.006 \\
\hline Stromal infiltration, $n(\%)$ & & & & $<0.001$ \\
\hline$<1 / 3$ & $112(61.2)$ & 0 & NA & \\
\hline $1 / 2$ to $2 / 3$ & $43(23.5)$ & $7(53.8)$ & 1 & \\
\hline$<2 / 3$ & $28(15.3)$ & $6(46.2)$ & $1.33(0.45-3.97)$ & 0.6 \\
\hline
\end{tabular}

CI: confidence interval; BMI: body mass index; NA; not applicable; chi-square test or Fisher's exact test for the comparison of categorical variables, and Student's $t$ test for continuous variables.

\subsection{Surgical Procedures and Adjuvant Treatment}

As shown in Table 2, the most common surgical procedure was type C1 radical hysterectomy, which was performed in $67.9 \%$ of the patients. Other salient data were use of uterine manipulator in $68.6 \%$ of patients, negative surgical margins in $97.5 \%$, and sentinel lymph node biopsy (SLNB) was not performed in $50.2 \%$. 
Table 2. Surgical and Adjuvant Characteristics.

\begin{tabular}{|c|c|c|c|c|}
\hline Variables & $\begin{array}{l}\text { All Patients } \\
(n=239)\end{array}$ & $\begin{array}{l}\text { Recurrence } \\
\quad(n=26)\end{array}$ & $\begin{array}{l}\text { Hazard Ratio } \\
\text { (95\% CI) }\end{array}$ & $\begin{array}{c}p \\
\text { Value }\end{array}$ \\
\hline Type of radical hysterectomy, $n(\%)$ & & & & 0.016 \\
\hline Trachelectomy & $1(0.49)$ & 0 & NA & \\
\hline A & $14(5.9)$ & 0 & NA & \\
\hline B1 & $52(21.9)$ & $1(3.8)$ & $0.12(0.01-0.90)$ & 0.037 \\
\hline B2 & $9(3.8)$ & $1(3.8)$ & $0.66(0.09-4.86)$ & 0.68 \\
\hline $\mathrm{C} 1$ & $161(67.9)$ & $24(92.3)$ & 1 & \\
\hline \multicolumn{5}{|l|}{ Use of uterine manipulator, $n(\%)$} \\
\hline No & $75(31.4)$ & $6(23.1)$ & 1 & \\
\hline Yes & $164(68.6)$ & $20(76.9)$ & $1.47(0.59-3.67)$ & \\
\hline \multicolumn{5}{|l|}{ Surgical margins status, $n(\%)$} \\
\hline Negative & $233(97.5)$ & $24(92.3)$ & 1 & \\
\hline Positive & $6(2.5)$ & $2(7.7)$ & $3.3(0.79-14.28)$ & 0.099 \\
\hline Sentinel lymph node, $n(\%)$ & & & & 0.013 \\
\hline Biopsy performed & $119(49.8)$ & $7(26.9)$ & 1 & \\
\hline Biopsy not performed & $120(50.2)$ & $19(73.1)$ & $1.47(0.59-3.67)$ & 0.040 \\
\hline Adjuvant treatment, $n(\%)$ & & & & 0.110 \\
\hline None & $178(74.5)$ & $16(61.5)$ & 1 & \\
\hline Yes & $61(25.5)$ & $10(38.5)$ & $1.76(0.79-3.88)$ & 0.161 \\
\hline Chemoradiotherapy, $n$ (\%) & $20(8.4)$ & $5(19.2)$ & & \\
\hline $\begin{array}{c}\text { Radiotherapy } \pm \text { brachytherapy, } n \\
(\%)\end{array}$ & $41(17.2)$ & $5(19.2)$ & & \\
\hline
\end{tabular}

CI: confidence interval; NA; not applicable; chi-square test or Fisher's exact test for the comparison of categorical variables, and Student's $t$ test for continuous variables.

Major intraoperative complications were recorded in $11(4.2 \%)$ patients, postoperative complications in $25(9.5 \%)$, and long-term complications in $6(2.4 \%)$ (Table S1).

\subsection{Recurrence and Risk Factors}

After a median follow-up of 51 months, recurrence was diagnosed in 26 patients ( $\leq$ IB1 or IIA1 stage), with a recurrence rate of $10.9 \%$. Vaginal recurrences were diagnosed in 8 patients, pelvic in 8 , lymph nodes in 3, and systemic in 3 . After 2 years of follow-up, recurrences were present in 14 patients (recurrence rate $5.9 \%$ ). In the univariate analysis, age, clinical and MRI tumor size, histological type, tumor grade, histological tumor size, and stromal infiltration were risk factors for recurrence (Table 1). In 19 (73.1\%) of the 26 patients with recurrence, SLNB was not performed with a hazard ratio (HR) of 1.47 (95\% confidence interval (CI) 0.59-3.67) ( $p=0.406$ ) (Table 2). Five recurrences had negative SLNB, and one had micrometastasis. In the multivariate analysis, independent risk factors for recurrence were clinical tumor size $>20 \mathrm{~mm}$, adenocarcinoma and other histological types, positive lymph nodes, tumor grades 2 and 3, and not having performed SLNB (Table 3).

Table 3. Results of Multivariate Analysis.

\begin{tabular}{ccc}
\hline Predictive Factors & $\begin{array}{c}\text { Hazard Ratio } \\
(\mathbf{9 5} \% \mathbf{C I})\end{array}$ & $p$ Value * \\
\hline Clinical tumor size $>20 \mathrm{~mm}$ & $2.37(1.05-6.07)$ & 0.038 \\
Histological type & & \\
Adenocarcinoma & $2.51(1.03-6.07)$ & 0.042 \\
Tumor grade & $4.36(1.14-16.61)$ & 0.031 \\
2 & $4.99(1.11-22.45)$ & 0.036 \\
3 & $8.06(1.68-38.6)$ & 0.009 \\
Other (mixed, sarcoma, clear cell, glassy cell) & $4.08(1.54-10.78)$ & 0.005 \\
SLNB not performed & $4.83(1.40-16.63)$ & 0.012 \\
Positive nodal status
\end{tabular}

CI: confidence interval; SLNB: sentinel lymph node biopsy; ${ }^{*}$ Wald chi-square test. 


\subsection{Oncological Outcomes}

The OS rate was $94.1 \%$ (225/239) and the DSF was $89.1 \%(213 / 239)$. The cancer specific mortality rate was $4.6 \%$ (11/239). There were statistically significant differences in DFS at 5 years when patients were grouped according to risk factors for recurrence (Table 4).

Table 4. Disease-Free Survival and Risk Factors for Recurrence.

\begin{tabular}{ccc}
\hline Variables & Disease-Free Survival, \% (95\% CI) & $p$ Value $^{*}$ \\
\hline Clinical tumor size & $89.3(82.6-95.9)$ & \\
$\leq 20 \mathrm{~mm}$ & $69.9(54.3-85.4)$ & 0.002 \\
$>20 \mathrm{~mm}$ & $90.1(84.3-95.9)$ & \\
Histological type & $76.4(63.5-89.4)$ & 0.008 \\
Squamous cell carcinoma & $60(24.9-95.1)$ & \\
Adenocarcinoma & $83.5(76.3-90.7)$ & 0.003 \\
Other & $52.9(19.4-86.5)$ & \\
Nodal status & $96.4(91.6-101.3)$ & 0.001 \\
Negative & $79.3(67.6-91)$ & \\
Positive & $69.2(53.4-85.1)$ & \\
Tumor grade & & 0.049 \\
1 & $87.1(75.7-98.6)$ & \\
2 & $79.6(71-88.3)$ & \\
3 & $* \log$-rank test.
\end{tabular}

The prognostic FIGO 2018 classification was found to be more accurate than FIGO 2009 classification system (Figure 1).
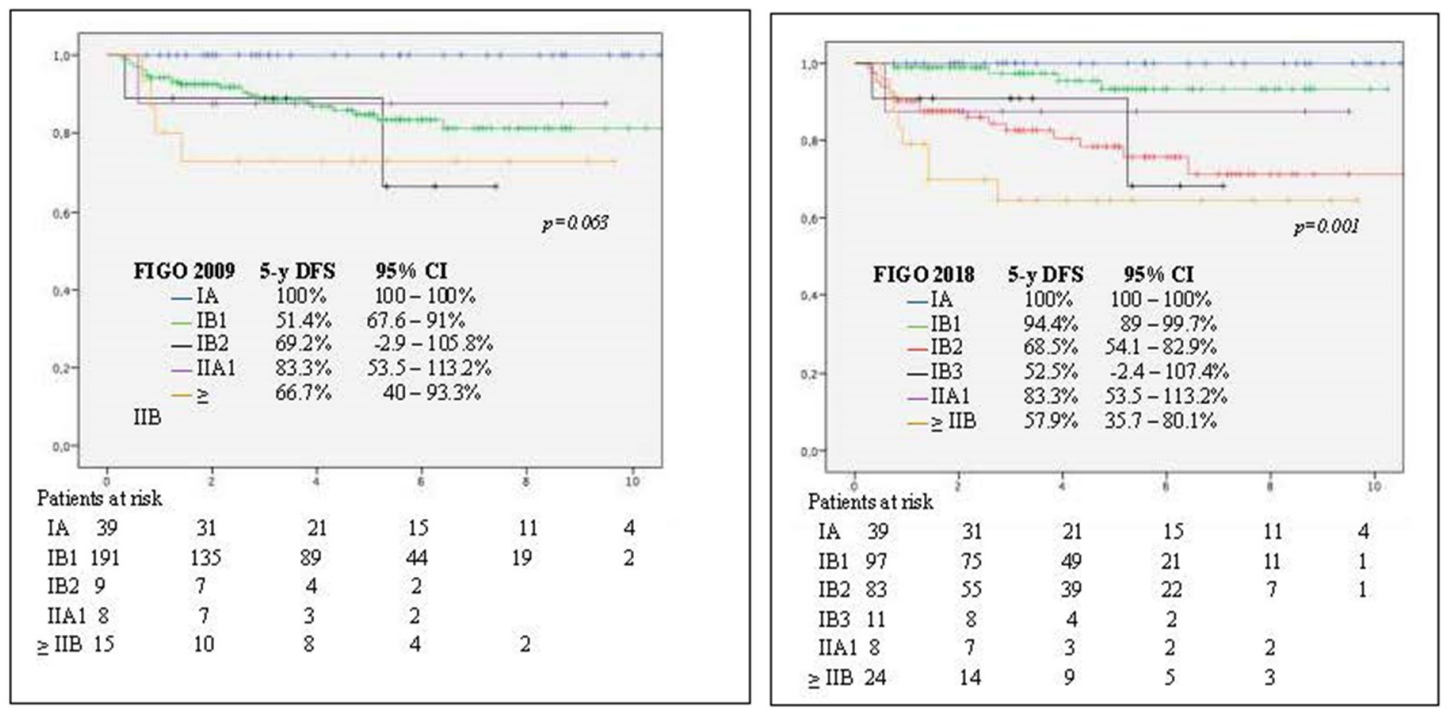

Figure 1. Kaplan-Meier analysis of disease-free survival (DFS) at 5 years. Differences between use of International Federation of Gynecology and Obstetrics (FIGO) 2009 (log-rank test, $p=0.063$ ) (left panel) and FIGO 2019 (log-rank test, $p=0.001$ ) (right panel) staging systems.

Finally, the result obtained in 231 patients (stages $\leq$ IB1) in terms of recurrence and oncological outcome were similar to those observed in all 263 women who underwent robot-assisted radical hysterectomy during the study period (Table S2). 


\subsection{Audit of Quality Indicators}

Five of six quality outcome indicators of the ESGO for surgical treatment of cervical cancer [17] were fulfilled, except for a higher percentage of patients receiving adjuvant therapy for a stage pT1b1 pN0 disease (Table 5).

Table 5. European Society of Gynecology Oncology (ESGO) Quality Indicators Related to Surgical Procedure for Cervical Cancer.

\begin{tabular}{|c|c|c|}
\hline Outcome Indicator & Target Value & Present Series \\
\hline QI 9-Urological fistula rate within 30 postoperative days after radical parametrectomy & $\leq 3 \%$ & $0 \%$ \\
\hline $\begin{array}{l}\text { QI 10-Proportion of patients after primary surgical treatment who have clear vaginal (invasive disease) and } \\
\text { parametrial margins }\end{array}$ & $\geq 97 \%$ & $97.3 \%(213 / 219)$ \\
\hline QI 11-Proportion of patients with a stage T1b disease T-upstaged after surgery & $<10 \%$ & $9.1 \%(24 / 263)$ \\
\hline QI 12-Recurrence rate at 2 years in patients with a stage pT1b1 with negative lymph nodes after surgery & $<10 \%$ & $5.1 \%(9 / 175)$ \\
\hline $\begin{array}{l}\text { QI 13-Proportion of patients with a T1 disease treated by primary surgery who underwent lymph node } \\
\text { staging }\end{array}$ & $\geq 98 \%$ & $99.6 \%(1 / 218)$ \\
\hline $\begin{array}{l}\text { QI 15-Proportion of patients receiving adjuvant chemoradiotherapy after a primary surgical treatment for a } \\
\text { stage pT1b1 pN0 disease }\end{array}$ & $<15 \%$ & $28.1 \%(44 / 182)$ \\
\hline
\end{tabular}

\section{Discussion}

In recent years, numerous studies compared oncological outcomes (OS and DFS) between open approach and MIS in women with cancer of the cervix. However, as far as we are aware, this is the first study which was specifically designed to audit the oncological and surgical outcomes among the national (Spain and Portugal) population of early-stage cervical cancer who underwent robotic surgery. Risk factors for recurrence after robot-assisted radical hysterectomy (ordered from the highest to the lowest risk) were tumor grade 3 , tumor grade 2, positive lymph nodes, histological aggressive subtypes, adenocarcinoma, not having performed SLNB, and clinical tumor size $>20 \mathrm{~mm}$. Moreover, our findings confirm that the FIGO 2018 staging system [22] is a better prognosticator of outcome as compared with the FIGO 2009 system [23] because of the inclusion of a new cut-off for tumor size $(2 \mathrm{~cm})$ and lymph node involvement.

Recent studies evaluated the oncological outcomes in patients with cervical tumors $\leq 20 \mathrm{~mm}$ [24-26]; in particular, the study of Anchora et al. [27] compared patients with 2009 FIGO stage from IA1 with lymphovascular space invasion to IB1/IIA1 treated by open or laparoscopic surgery and found that laparoscopic and open approaches showed superimposable DFS. A tumor diameter of $20 \mathrm{~mm}$ was considered as the choice of surgical approach, with recommendation of open surgery for tumors $>20 \mathrm{~mm}$ and either laparoscopic or open surgery for tumors $<20 \mathrm{~mm}$ [27]. However, in a retrospective study of 815 women with tumor size $\leq 20 \mathrm{~mm}$, in whom radical hysterectomy was performed by MIS in 255 cases and open surgery in 560 cases, the MIS approach was noted to be independently associated with a higher likelihood of recurrence (adjusted HR, 6.31;95\% CI 1.24-31.9) [28]. Candidates in our study we eligible women for robotic surgery from the beginning of the initiation of robotic surgery programs up to 2018, but given the retrospective analysis of data, outcomes in tumors sizes $\leq 20 \mathrm{~mm}$ and $>20 \mathrm{~mm}$ were evaluated. Interestingly, clinical tumor size $>20 \mathrm{~mm}$ was a predictor of recurrence but showed the lowest HR as compared to other variables. Therefore, pathological factors such as histological subtype and tumor grade should also be considered when deciding to perform minimally invasive radical hysterectomy for early-stage cervical cancer [29]. In a nationwide population-based cohort study carried out in Sweden with 864 women with cervical cancer stage IA1-IB undergoing radical hysterectomy in 2011-2017 (open surgery 236, robotic 628), tumor size and grade 3 were significant risk factors for DFS but not for OS, although risk factors for recurrence were not analyzed [30].

In addition, in case of selection of MIS, ESGO [16] recommends to collect data prospectively and to take extreme precautions to avoid tumor spillage [31], including ligation of the upper vagina before the laparoscopic procedure and to abandon uterine manipulator, considered as a risk factor for recurrence. The SUCCOR study published by Chiva et al. [32] observed that patients who underwent MIS without the use of a uterine manipulator had similar disease-free-survival to the open surgery 
group (HR, 1.58; 95\% CI, 0.79 to $3.15 ; p=0.20)$. By contrast, in our study, there was a non-significant $4 \%$ increase in recurrence among patients in whom the uterine manipulator was used.

A further interesting aspect of the study was the prognostic impact of not having performed SLNB, with a statistically significant likelihood of recurrence of 4.08 (95\% CI 1.54-10.78). Sentinel node biopsy is a valuable procedure for a more accurate diagnosis of nodal involvement and for reducing lymphatic morbidity as an alternative option to standard pelvic lymphadenectomy. In this respect, an international validation study (SENTICOL III) of SLNB in women with early-stage cancer of the cervix with last accrual scheduled in 2021 and last follow-up in 2026, will provide conclusive data of 3-year DFS after SLN biopsy alone or SLN+ pelvic lymphadenectomy [33]. The intraoperative diagnosis of macrometastases is crucial to avoid overtreatment for patients with advanced stages who would benefit from chemoradiotherapy [34].

As mentioned above, the present results of robotic surgery were evaluated according to the QI for cervical cancer surgery proposed by the ESGO [17] in January 2020. Of note, our results of indicators related to the quality of surgical procedures were all beyond the proposed targets. On the other hand, those results are inferior to the open surgery reported of LACC [13] where the 4.5 years DFS was $96.5 \%$. Should the QI be revised on the basis of this cut-off in order to increase the level of excellence in gynecological oncology? In case of fulfilling the QI, is either approach permitted? Results of the currently ongoing international randomized multicenter RAAC trial (robot-assisted approach to cervical cancer) [35] will provide important data of recurrence-free survival at 5 years between women treated with robot-assisted laparoscopic surgery versus laparotomy for early-stage cervical cancer. In the meantime, the MIS approach should be performed by highly experienced surgical centers.

Limitations of the study include the retrospective design and small sample size due to difficulties related to the absence of strict centralization of cervical cancer cases associated with the low prevalence of cancer of the cervix as compared to studies carried out in other countries [35]. However, selection bias was reduced by selecting all consecutive eligible women undergoing robotic surgery for early-stage cervical cancer based on the total number of departments of gynecology in Spanish and Portuguese hospitals with availability of robotic technology during the study period. Although this study may be considered regionally specific, the novel aspect is the assessment of results obtained with robot-assisted radical surgery in early-stage cervical cancer patients as the only surgical approach.

\section{Materials and Methods}

\subsection{Study Design and Participants}

All patients diagnosed with early-stage cervical cancer undergoing robot-assisted radical hysterectomy in Spain and Portugal were eligible for inclusion in a retrospective cohort multicenter study. Inclusion criteria were as follows: infiltrating cervical cancer diagnosed on biopsy, to be candidates for radical surgery according to FIGO 2009 classification [23], and to be operated on by robotic surgery from the beginning of the initiation of robotic surgery programs up to 2018. All cases were collected from 10 tertiary care hospitals, 9 in Spain and 1 in Portugal. The primary objective of the study was to assess risk factors for recurrence. A second primary objective was to audit the surgical results according to recommendations of quality indicators for cervical cancer surgery proposed by the ESGO [17]. Secondary objectives were to assess oncological outcomes and to validate the FIGO 2018 classification. All patients gave written informed consent for the surgical procedure.

\subsection{Surgical Procedure and Adjuvant Treatment}

The type of radical hysterectomy was left at the discretion of the attending surgeon and categorized according to the Querleu-Morrow classification [36] and the use of uterine manipulator. All operations were performed using the da Vinci ${ }^{\circledR}$ surgical system. Pelvic lymph node status was evaluated by means of SLNB and/or pelvic lymphadenectomy depending on the surgeon's criterion. Positive pelvic lymph nodes gathered all patients with positive lymph nodes including micrometastases or isolated 
tumor cells after SLNB ultrastaging. The SLNB was detected by technetium \pm blue dye or indocyanine green (ICG) or ICG alone. Macrometastasis or micrometastasis and isolated tumor cells were analyzed in the SLNB ultrastaging procedure. When the presence of macrometastases was diagnosed in frozen section intraoperatively, radical hysterectomy was not performed. Postoperative adjuvant treatment was indicated depending on the center's protocol for the management of cervical cancer, taking into account the FIGO stage, risk factors, or positive margins. Adjuvant treatment included external-beam radiotherapy ( $50 \mathrm{~Gy} / 5$ weeks) \pm brachytherapy \pm chemotherapy (cisplatin $40 \mathrm{mg} / \mathrm{m}^{2}$ every week during external radiation therapy).

\subsection{Oncological Outcomes and Audit of Quality Indicators}

Recurrence of the disease was diagnosed by the combination of clinical, radiological, and histological findings. The time elapsed from the date of radical hysterectomy to diagnosis of recurrence was used to define DFS, and the date of operation to death from any cause to define OS. The audit of oncological outcomes was performed by comparison of the results obtained with recommended targets of QI proposed by the ESGO [17]. From 15 QI specifically designed for the analysis of surgical or treatment outcomes, 5 surgical QI and 1 adjuvant treatment QI were selected.

\subsection{Data Collection}

Clinical and pathological variables were collected and included age, body mass index (BMI, $\left.\mathrm{kg} / \mathrm{m}^{2}\right)$, clinical tumor size by inspection or ultrasound, size measured by MRI, tumor histology, FIGO stage after surgery, histologic tumoral size, surgical margins, presence of invasion of the lymphovascular space (LVSI), infiltration of the stroma, and tumor grade. LVSI was diagnosed when malignant cells were present in epithelial-lined spaces of the cervical stroma. The depth of stromal infiltration from the basement membrane was measured in millimeters and expressed as thirds of the total stromal width. The pathologist measured the size of the cervical tumor as the largest diameter on the cone and gross tissue samples. Complications included grade II-IV complications recorded intraoperatively [37] during the first 30 postoperative days (early complications) and after 30 days of surgery (late complications) [38].

\subsection{Statistical Analysis}

Categorical variables are reported as absolute numbers and percentages. Mean values and standard deviation (SD) or median values and range (minimum-maximum) were used to express quantitative variables. Categorical variables were analyzed with the chi-square test of the Fisher's exact test, whereas continuous variables were analyzed with the Student's $t$ test. Risk factors for recurrence of cervical cancer were determined by Cox proportional hazards regression analysis, with hazard ratios (HRs) with 95\% confidence intervals (CIs) as the measures of risk. Oncological outcomes, OS and DFS, were calculated with the Kaplan-Meier method, with differences in the probability of survival analyzed with the log-rank test. The date of the last follow-up was the censored date for patients without events. The IBM SPSS Version 23.0 and R 3.0.3 program was used for statistical analysis. A $p$ value of $<0.05$ was considered statistically significant.

\section{Conclusions}

In this study of women with early-stage cervical cancer undergoing robot-assisted radical hysterectomy, risk factors for recurrence were tumor grade, adenocarcinoma and aggressive histological subtypes, clinical tumor size, positive lymph nodes, and lack of performance of intraoperative SLNB. Therefore, when considering robotic surgery for the management of $\leq$ IB1 cervical cancer, careful selection of patients would include tumors $<20 \mathrm{~mm}$, squamous cell carcinoma histological type, tumors grade 1, and to perform SLNB intraoperatively in order to reduce the likelihood of recurrence. The quality of surgical outcomes obtained in the present series was beyond recommended quality targets for cervical cancer surgery. 
Supplementary Materials: The following are available online at http://www.mdpi.com/2072-6694/12/11/3387/s1: Table S1: Major surgical complications, Table S2: Oncological outcomes \& Recurrences.

Author Contributions: Conceptualization: J.P., M.B. (Manel Barahona) and S.F.-G. Methodology: J.P. and S.F.-G. Formal analysis: J.P. and S.F.-G. Data curation: M.B. (Marc Barahona), J.P. and S.F.-G. Writing-original: J.P. and S.F.-G. Draft preparation, J.P., S.F.-G., A.G.-M., P.J.C., Review and editing, J.D.1.R., H.N., G.H., A.T., J.G.-E., S.M.-R., M.B. (Marc Barahona), M.Á.M.-M. Supervisión: J.P., M.B. (Manel Barahona), J.D.1.R., H.N., G.H., A.T., J.G.-E., S.M.-R., M.B. (Marc Barahona), M.Á.M.-M. All authors have read and agree to the published version of the manuscript.

Funding: This research received no external funding.

Acknowledgments: The authors thank Marta Pulido, for editing the manuscript and editorial assistance.

Conflicts of Interest: The authors declare no conflict of interest.

\section{References}

1. Nezhat, A.B.; Burrell, M.O.; Nezhat, M.R.; Benigno, C.E.W. Laparoscopic radical hysterectomy with paraaortic and pelvic node dissection. Am. J. Obstet. Gynecol. 1992, 166, 864-865. [CrossRef]

2. Jennings, T.S.; Dottino, P.; Rahaman, J.; Cohen, C.J. Results of selective use of operative laparoscopy in gynecologic oncology. Gynecol. Oncol. 1998, 70, 323-328. [CrossRef]

3. Advincula, A.P. Surgical techniques: Robot-assisted laparoscopic hysterectomy with the da Vinci surgical system. Int. J. Med. Robot. Comput. Assist. Surg. 2006, 2, 305-311. [CrossRef]

4. Sert, B.M.; Aveler, V.M. Robot-assisted laparoscopic radical hysterectomy (Piver III) with pelvic node dissection-Case report. Eur. J. Gynaecol. Oncol. 2006, 27, 531-533.

5. Nam, J.H.; Park, J.Y.; Kim, D.Y.; Kim, J.H.; Kim, Y.M.; Kim, Y.T. Laparoscopic versus open radical hysterectomy in early-stage cervical cancer: Long-term survival outcomes in a matched cohort study. Ann. Oncol. 2012, 23, 903-911. [CrossRef] [PubMed]

6. Park, J.Y.; Kim, D.Y.; Kim, J.H.; Kim, Y.M.; Kim, Y.T.; Nam, J.H. Laparoscopic versus open radical hysterectomy in patients with stage IB2 and IIA2 cervical cancer. J. Surg. Oncol. 2013, 108, 63-69. [CrossRef] [PubMed]

7. Wang, Y.Z.; Deng, L.; Xu, H.C.; Zhang, Y.; Liang, Z.Q. Laparoscopy versus laparotomy for the management of early stage cervical cancer. BMC Cancer 2015, 15, 928. [CrossRef] [PubMed]

8. Cantrell, L.A.; Mendivil, A.; Gehrig, P.A.; Boggess, J.F. Survival outcomes for women undergoing type III robotic radical hysterectomy for cervical cancer: A 3-year experience. Gynecol. Oncol. 2010, 117, 260-265. [CrossRef] [PubMed]

9. Sert, B.M.; Boggess, J.F.; Ahmad, S.; Jackson, A.L.; Stavitzski, N.M.; Dahl, A.A.; Holloway, R.W. Robot-assisted versus open radical hysterectomy: A multi-institutional experience for early-stage cervical cancer. Eur. J. Surg. Oncol. 2016, 42, 513-522. [CrossRef]

10. Mendivil, A.A.; Rettenmaier, M.A.; Abaid, L.N.; Brown, J.V., 3rd; Micha, J.P.; Lopez, K.L.; Goldstein, B.H. Survival rate comparisons amongst cervical cancer patients treated with an open, robotic-assisted or laparoscopic radical hysterectomy: A five year experience. Surg. Oncol. 2016, 25, 66-71. [CrossRef]

11. Shah, C.A.; Beck, T.; Liao, J.B.; Giannakopoulos, N.V.; Veljovich, D.; Paley, P. Surgical and oncologic outcomes after robotic radical hysterectomy as compared to open radical hysterectomy in the treatment of early cervical cancer. J. Gynecol. Oncol. 2017, 28, e82. [CrossRef] [PubMed]

12. Hoogendam, J.P.; Verheijen, R.H.; Wegner, I.; Zweemer, R.P. Oncological outcome and long-term complications in robot-assisted radical surgery for early stage cervical cancer: An observational cohort study. BJOG 2014, 121, 1538-1545. [CrossRef] [PubMed]

13. Ramirez, P.T.; Frumovitz, M.; Pareja, R.; Lopez, A.; Vieira, M.; Ribeiro, R.; Buda, A.; Yan, X.; Shuzhong, Y.; Chetty, N.; et al. Minimally invasive versus abdominal radical hysterectomy for cervical cancer. N. Engl. J. Med. 2018, 379, 1895-1904. [CrossRef] [PubMed]

14. Melamed, A.; Margul, D.J.; Chen, L.; Keating, N.L.; Del Carmen, M.G.; Yang, J.; Seagle, B.L.; Alexander, A.; Barber, E.L.; Rice, L.W.; et al. Survival after minimally invasive radical hysterectomy for early-stage cervical cancer. N. Engl. J. Med. 2018, 379, 1905-1914. [CrossRef] [PubMed] 
15. British Gynaecological Cancer Society. National Cancer Registration and Analysis Service. Comparisons of Overall Survival in Women Diagnosed with early Stage Cervical Cancer during 2013-2016, Treated by Radical Hysterectomy Using Minimal access or Open Approach. Available online: https://www.bgcs.org.uk/ ncras-cervical-cancer-radical-hysterectomy-analysis/ (accessed on 22 September 2020).

16. Querleu, D.; Cibula, D.; Concin, N.; Fagotti, A.; Ferrero, A.; Fotopoulou, C.; Knapp, P.; Kurdiani, D.; Ledermann, J.A.; Mirza, M.R.; et al. Laparoscopic radical hysterectomy: A European Society of Gynaecological Oncology (ESGO) statement. Int. J. Gynecol. Cancer 2020, 30, 15. [CrossRef] [PubMed]

17. Cibula, D.; Planchamp, F.; Fischerova, D.; Fotopoulou, C.; Kohler, C.; Landoni, F.; Mathevet, P.; Naik, R.; Ponce, J.; Raspagliesi, F.; et al. European Society of Gynaecological Oncology quality indicators for surgical treatment of cervical cancer. Int. J. Gynecol. Cancer 2020, 30, 3-14. [CrossRef]

18. Bray, F.; Ferlay, J.; Soerjomataram, I.; Siegel, R.L.; Torre, L.A.; Jemal, A. Global cancer statistics 2018: GLOBOCAN estimates of incidence and mortality worldwide for 36 cancers in 185 countries. CA Cancer J. Clin. 2018, 68, 394-424. [CrossRef] [PubMed]

19. Arbyn, M.; Weiderpass, E.; Bruni, L.; de Sanjosé, S.; Saraiya, M.; Ferlay, J.; Bray, F. Estimates of incidence and mortality of cervical cancer in 2018: A worldwide analysis. Lancet Glob. Health 2020, 8, e191-e203. [CrossRef]

20. Vaccarella, S.; Lortet-Tieulent, J.; Plummer, M.; Franceschi, S.; Bray, F. Worldwide trends in cervical cancer incidence: Impact of screening against changes in disease risk factors. Eur. J. Cancer 2013, 49, 3262-3273. [CrossRef] [PubMed]

21. de Juan, A.; Redondo, A.; Rubio, M.J.; García, Y.; Cueva, J.; Gaba, L.; Yubero, A.; Alarcón, J.; Maximiano, C.; Oaknin, A. SEOM clinical guidelines for cervical cancer (2019). Clin. Transl. Oncol. 2020, 22, 270-278. [CrossRef] [PubMed]

22. Bhatla, N.; Aoki, D.; Sharma, D.N.; Sankaranarayanan, R. Cancer of the cervix uteri. Int. J. Gynaecol. Obstet. 2018, 143 (Suppl. S2), 22-36. [CrossRef] [PubMed]

23. FIGO Committee on Gynecologic Oncology. Revised FIGO staging for carcinoma of the vulva, cervix, and endometrium. Int. J. Gynaecol. Obstet. 2009, 105, 103-104. [CrossRef] [PubMed]

24. Chen, X.; Zhao, N.; Ye, P.; Chen, J.; Nan, X.; Zhao, H.; Zhou, K.; Zhang, Y.; Xue, J.; Zhou, H.; et al. Comparison of laparoscopic and open radical hysterectomy in cervical cancer patients with tumor size $\leq 2 \mathrm{~cm}$. Int. J. Gynecol. Cancer 2020, 30, 564-571. [CrossRef] [PubMed]

25. Kim, S.I.; Cho, J.H.; Seol, A.; Kim, Y.I.; Lee, M.; Kim, H.S.; Chung, H.H.; Kim, J.W.; Park, N.H.; Song, Y.S. Comparison of survival outcomes between minimally invasive surgery and conventional open surgery for radical hysterectomy as primary treatment in patients with stage IB1-IIA2 cervical cancer. Gynecol. Oncol. 2019, 153, 3-12. [CrossRef] [PubMed]

26. Pareja, R. Safety of minimally invasive radical hysterectomy in cervical tumors $<2 \mathrm{~cm}$. Int. J. Gynecol. Cancer 2020, 30, 572-574. [CrossRef] [PubMed]

27. Pedone Anchora, L.; Turco, L.C.; Bizzarri, N.; Capozzi, V.A.; Lombisani, A.; Chiantera, V.; De Felice, F.; Gallotta, V.; Cosentino, F.; Fagotti, A.; et al. How to select early-stage cervical cancer patients still suitable for laparoscopic radical hysterectomy: A propensity-matched study. Ann. Surg. Oncol. 2020, 27, 1947-1955. [CrossRef] [PubMed]

28. Uppal, S.; Gehrig, P.A.; Peng, K.; Bixel, K.L.; Matsuo, K.; Vetter, M.H.; Davidson, B.A.; Cisa, M.P.; Lees, B.F.; Brunette, L.L.; et al. Recurrence rates in patients with cervical cancer treated with abdominal versus minimally invasive radical hysterectomy: A multi-institutional retrospective review study. J. Clin. Oncol. 2020, 38, 1030-1040. [CrossRef]

29. Vergote, I.; Magrina, J.F.; Zanagnolo, V.; Magtibay, P.M.; Butler, K.; Gil-Moreno, A.; Feijoo, B.D.; Kimmig, R.; Canis, M.; Bourdel, N.; et al. The LACC trial and minimally invasive surgery in cervical cancer. J. Minim. Invasive Gynecol. 2020, 27, 462-463. [CrossRef]

30. Alfonzo, E.; Wallin, E.; Ekdahl, L.; Staf, C.; Rådestad, A.F.; Reynisson, P.; Stålberg, K.; Falconer, H.; Persson, J.; Dahm-Kähler, P. No survival difference between robotic and open radical hysterectomy for women with early-stage cervical cancer: Results from a nationwide population-based cohort study. Eur. J. Cancer 2019, 116, 169-177. [CrossRef]

31. Yuan, P.; Liu, Z.; Qi, J.; Yang, X.; Hu, T.; Tan, H. Laparoscopic radical hysterectomy with enclosed colpotomy and without the use of uterine manipulator for early-stage cervical cancer. J. Minim. Invasive Gynecol. 2019, 26, 1193-1198. [CrossRef] 
32. Chiva, L.; Zanagnolo, V.; Querleu, D.; Martin-Calvo, N.; Arévalo-Serrano, J.; Emil, C.; Căpîlna, M.E.; Fagotti, A.; Kucukmetin, A.; Mom, C.; et al. SUCCOR study: An international European cohort observational study comparing minimally invasive surgery versus open abdominal radical hysterectomy in patients with stage IB1 cervical cancer. Int. J. Gynecol. Cancer 2020, 39, 1269-1277. [CrossRef] [PubMed]

33. Lecuru, F.R.; McCormack, M.; Hillemanns, P.; Anota, A.; Leitao, M.; Mathevet, P.; Zweemer, R.; Fujiwara, K.; Zanagnolo, V.; Zahl Eriksson, A.G.; et al. SENTICOL III: An international validation study of sentinel node biopsy in early cervical cancer. A GINECO, ENGOT, GCIG and multicenter study. Int. J. Gynecol. Cancer 2019, 20, 829-834. [CrossRef] [PubMed]

34. Chemoradiotherapy for Cervical Cancer Meta-Analysis Collaboration. Reducing uncertainties about the effects of chemoradiotherapy for cervical cancer: A systematic review and meta-analysis of individual patient data from 18 randomized trials. J. Clin. Oncol. 2008, 26, 5802-5812. [CrossRef]

35. Falconer, H.; Palsdottir, K.; Stalberg, K.; Dahm-Kähler, P.; Ottander, U.; Lundin, E.S.; Wijk, L.; Kimmig, R.; Jensen, P.T.; Zahl Eriksson, A.G.; et al. Robot-assisted approach to cervical cancer (RACC): An international multi-center, open-label randomized controlled trial. Int. J. Gynecol. Cancer 2019, 29, 1072-1076. [CrossRef] [PubMed]

36. Querleu, D.; Cibula, D.; Abu-Rustum, N.R. 2017 Update on the Querleu-Morrow classification of radical hysterectomy. Ann. Surg. Oncol. 2017, 24, 3406-3412. [CrossRef]

37. Rosenthal, R.; Hoffmann, H.; Clavien, P.A.; Bucher, H.C.; Dell-Kuster, S. Definition and Classification of Intraoperative Complications (CLASSIC): Delphi study and pilot evaluation. World J. Surg. 2015, 39, 1663-1671. [CrossRef]

38. Clavien, P.A.; Barkun, J.; de Oliveira, M.L.; Vauthey, J.N.; Dindo, D.; Schulick, R.D.; de Santibañes, E.; Pekolj, J.; Slankamenac, K.; Bassi, C.; et al. The Clavien-Dindo classification of surgical complications: Five-year experience. Ann. Surg. 2009, 250, 187-196. [CrossRef]

Publisher's Note: MDPI stays neutral with regard to jurisdictional claims in published maps and institutional affiliations.

(C) 2020 by the authors. Licensee MDPI, Basel, Switzerland. This article is an open access article distributed under the terms and conditions of the Creative Commons Attribution (CC BY) license (http://creativecommons.org/licenses/by/4.0/). 